\title{
Association between Sleep Duration and Incident Chronic Kidney Disease: A Population-Based Cohort Analysis of the NAGALA Study
}

\author{
Hanako Nakajima ${ }^{a}$ Yoshitaka Hashimoto ${ }^{a}$ Takuro Okamura ${ }^{a}$ \\ Akihiro Obora $^{\mathrm{b}}$ Takao Kojima ${ }^{\mathrm{b}}$ Masahide Hamaguchi ${ }^{\mathrm{a}}$ Michiaki Fukui ${ }^{\mathrm{a}}$ \\ aDepartment of Endocrinology and Metabolism, Graduate School of Medical Science, \\ Kyoto Prefectural University of Medicine, Kyoto, Japan; ${ }^{b}$ Department of Gastroenterology, \\ Asahi University Hospital, Gifu, Japan
}

\section{Keywords}

Chronic renal failure $\cdot$ Epidemiology $\cdot$ Risk factors $\cdot$ Sleep duration

\begin{abstract}
Background: The duration of sleep might be a risk factor for chronic kidney disease (CKD). We investigated the relationship between sleep duration and incident CKD. Methods: In this retrospective cohort study of 7,752 men and 6,722 women, we divided the subjects into 4 groups according to sleep duration, i.e., those whose reported regular sleep duration was $<6 \mathrm{~h}$ (the " $<6$ h group"), those whose sleep duration was $>6$ but $<7$ h (the " 6 to $<7$ h group"), those with a sleep duration of 7 to $<8 \mathrm{~h}$ (the "7 to $<8 \mathrm{~h}$ group"), and those with $\geq 8 \mathrm{~h}$ sleep (the " $\geq 8 \mathrm{~h}$ group"). CKD was defined as the presence of proteinuria and/or an estimated glomerular filtration rate (eGFR) $<60 \mathrm{~mL} / \mathrm{min} / 1.73 \mathrm{~m}^{2}$. The HR of the 4 groups for incident CKD were calculated with a Cox proportional hazards model, with the 7 to $<8 \mathrm{~h}$ group set as the reference. Results: Incident CKD was detected in 1,513 (19.5\%) men and 688 (10.2\%) women over the median follow-up period of 7.0 (3.3-11.9) years in the men and 6.7 (3.1-10.8) years in the women. There was no association between sleep duration and incident CKD in the women. In the men, the HR of incident CKD was $0.54(95 \% \mathrm{Cl} 0.45-0.64, p<0.001)$ in the $<6 \mathrm{~h}$ group, 0.73 ( $95 \% \mathrm{Cl} 0.66-0.82, p<0.001)$ in the 6 to $<7 \mathrm{~h}$ group, and 0.93 (95\% Cl $0.78-1.11$, $p=0.433$ ) in the $\geq 8 \mathrm{~h}$ group. Conclusion: The risk of incident CKD is lowest in those who sleep $<6 \mathrm{~h}$. We revealed that the risk of incident CKD is lowest in those who sleep $<6 \mathrm{~h}$ among apparently healthy men.




\section{Kidney \\ Blood Pressure \\ Research}

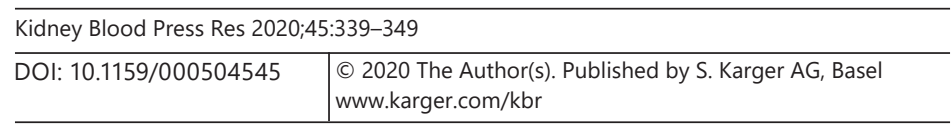

Nakajima et al.: CKD and Sleep Duration

\section{Introduction}

Among the several factors that are known to present a risk for the development of endstage renal disease, chronic kidney disease (CKD) is the most important [1-3]. CKD is also a risk factor for cardiovascular morbidity and mortality [1-3]. The number of individuals with CKD is markedly increasing worldwide, and it has been estimated that $12.5 \%$ of the people in Japan have CKD [4]. The changes in the prevalence of CKD are speculated to be a result of the broad prevalence and severity of diabetes and hypertension, which have also become more common due to unhealthy lifestyles. Hypertension, type 2 diabetes, obesity, and cardiovascular disease are important risk factors in the development and progression of CKD [5].

Lifestyle-related factors such as the excessive consumption of salt, calories, and fat and the use of tobacco products (e.g., cigarettes) are established risk factors for the abovementioned diseases $[6,7]$. Lifestyle modifications are thus thought to be required for the prevention of hypertension, type 2 diabetes, obesity, and cardiovascular disease. Similarly, the development of CKD might be prevented, directly and/or indirectly, by lifestyle modifications [8]. Several studies have revealed that an individual's habitual duration of sleep is associated with increased risks of hypertension [9], type 2 diabetes [10,11], obesity [12], nonalcoholic fatty liver disease $[13,14]$, and cardiovascular disease $[15,16]$.

A recent meta-analysis revealed that short sleep duration tended to be associated with the prevalence of CKD [17], although the tendency was not significant. Other than this finding, little is known about the precise association between sleep duration and incident CKD [18]. The optimal duration of sleep that would help prevent CKD and other diseases is not known. A single study (of shift workers) indicated that a short sleep duration poses a risk of incident CKD [19]. We conducted the present analyses to clarify the relationship between individuals' habitual sleep duration at a baseline examination and incident CKD in a large-scale cohort study of a healthy Japanese population.

\section{Materials and Methods}

\section{Study Population}

The present study is a subanalysis of the NAGALA (NAfld in Gifu Area, Longitudinal Analysis) study, the details of which are described elsewhere [18]. Briefly, the NAGALA study is a historical cohort study of subjects who underwent a medical health checkup at Asahi University Hospital (Gifu, Japan). Many companies in Japan recommend an annual health checkup for their employees. Because many participants employed by several companies were expected to have repeated examinations, we took advantage of the opportunity to conduct a follow-up study. After obtaining informed consent and masking personal identifiable information, the medical data of the subjects were stored in a database. For the present analyses, we extracted the data of the subjects who underwent the medical checkup only once from 1994 to 2013 and whose eGFR was $<60 \mathrm{~mL} / \mathrm{min} / 1.73 \mathrm{~m}^{2}$ at the baseline examination.

The exclusion criteria were as follows: missing data of covariates (including body weight, high-density lipoprotein [HDL] cholesterol, and lifestyle factors); the use of regular medications such as medicine for hypertension, diabetes, dyslipidemia, hyperuricemia, or insomnia (1-time medicine such as painkillers and antibiotics are not included); the presence of CKD at the baseline examination; and no follow-up examinations. The reason we excluded participants with regular medications is that we wanted to determine the relationship between sleep time and development of incident CKD without any influence of the health baseline of each participant. We checked these points at each visit during the study period. The primary endpoint of this study was the development of CKD. 


\section{Kidney \\ Blood Pressure \\ Research}

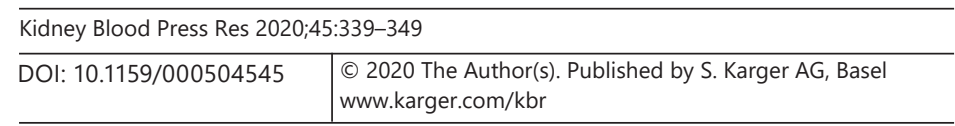

Nakajima et al.: CKD and Sleep Duration

\section{Data Collection}

The medical history and lifestyle factors of the subjects were obtained with a self-administered questionnaire [19]. The mean alcohol intake per week was estimated based on the data of the amounts and types of alcoholic beverages consumed per week. We then divided the subjects into the following 4 groups: no or minimal alcohol consumption, $<40 \mathrm{~g} /$ week; light alcohol consumption, 40-140 g/week; moderate alcohol consumption, 140-280 g/ week; and heavy alcohol consumption, >280 g/week [20, 21]. Smoking status was categorized into the following 3 groups: never-, ex-, and current smokers. "Exerciser" was defined as regularly performing any type of sport $\geq 1 \times /$ week [22].

The questionnaire also asked the subjects about their sleep duration, which was defined as the total time in bed per day. The subjects' BMI was calculated as body weight $(\mathrm{kg})$ divided by height $(\mathrm{m})$ squared. Fasting plasma glucose, creatine, uric acid, triglycerides, and HDL cholesterol were measured using the subjects' venous blood after an overnight fast. The estimated glomerular filtration rate (eGFR) was determined using the following equation of the Japanese Society of Nephrology: eGFR $=194 \times \mathrm{Cre}^{-1.094} \times \mathrm{age}^{-0.287}\left(\mathrm{~mL} / \mathrm{min} / 1.73 \mathrm{~m}^{2}\right)(\times 0.739$ for women) [23]. After the subject's overnight fast, we also gathered urine samples collected from mid-flow. Proteinuria was determined using dipstick testing (positive: 1+ or greater) $[24,25]$. CKD was defined as 2 measurements of either proteinuria or an eGFR of $<60 \mathrm{~mL} /$ $\mathrm{min} / 1.73 \mathrm{~m}^{2}[25]$ at least 90 days apart.

\section{Statistical Analyses}

Statistical analyses were performed using JMP software (version 13.2; SAS, Cary, NC, USA). $p<0.05$ was considered statistically significant. We analyzed both the entire series and the men and women separately. Continuous variables were presented as means \pm SD and categorical variables as numbers.

We divided the subjects into the following 4 groups based on sleep duration: those who reported sleeping $<6 \mathrm{~h}$ (the " $<6 \mathrm{~h}$ group"), those whose sleep duration was $>6$ but $<7 \mathrm{~h}$ (the " 6 to $<7$ h group"); those with a sleep duration of 7 to $<8 \mathrm{~h}$ (the " 7 to $<8 \mathrm{~h}$ group"); and those with $\geq 8$ h sleep (the " $\geq 8$ h group") [26]. The clinical characteristics of the 4 groups at their baseline examination were compared. The groups' continuous variables were evaluated by a one-way analysis of variance (ANOVA) and Tukey's honestly significant difference test, and categorical variables were evaluated using Pearson's $\chi^{2}$ test. We also evaluated the difference in sleep duration and change in creatinine $(\mathrm{Cr})$, defined as $(\mathrm{Cr}$ of the follow-up examination - Cr of the baseline examination)/Cr of the baseline examination/follow-up duration by scatter plot and linear regression analysis.

Kaplan-Meier analysis was used for a graphical presentation of the time to incident CKD, and a log-rank test was used to assess differences among groups. To correct for family-wise error, we performed a Bonferroni correction and $p<0.0083$ was considered statistically significant in the log-rank test. Because of the presence of censored cases and the inconsistent follow-up duration, we used the Cox proportional hazards model and calculated the HR of the 4 sleep duration groups. We considered several potential confounders as covariants, i.e., age, sex, alcohol consumption, smoking status, exercise, BMI, creatine, uric acid, triglycerides, and systolic blood pressure.

\section{Results}

We found that 19,137 subjects in the NAGALA database satisfied the inclusion criteria of the present study; 4,653 subjects were excluded based on the above described exclusion criteria (Fig. 1). Some of the participants overlapped the exclusion criteria. Our study popu- 


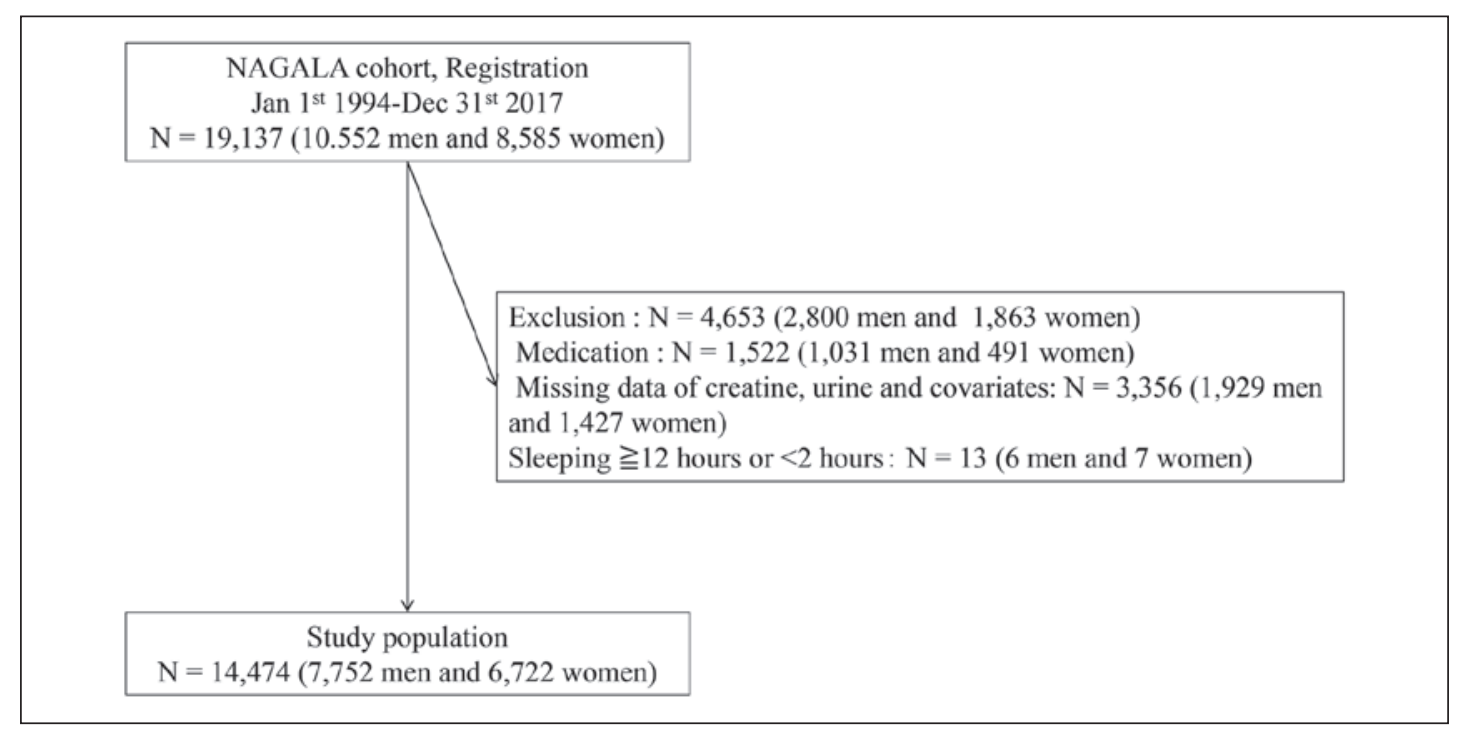

Fig. 1. Flow chart of the participants.

lation thus consisted of 14,474 subjects ( 7,752 men and 6,722 women). The subjects' baseline characteristics are summarized in Table 1.

Over the median (IQR) follow-up period of 7.0 (3.3-11.9) years in the men and 6.7 (3.110.8) years in the women, incident CKD was detected in 1,513 (19.5\%) men and $688(10.2 \%)$ women. Among the men, the crude number (proportion) of incident CKD cases was 167 $(12.5 \%)$ in the $<6$ h group, $588(17.5 \%)$ in the 6 to $<7$ h group, $608(25.0 \%)$ in the 7 to $<8 \mathrm{~h}$ group, and 150 (24.2\%) in the $\geq 8 \mathrm{~h}$ group. Among the women, the crude number (proportion) of incident CKD cases was $112(9.4 \%)$ in the $<6$ h group, $316(10.7 \%)$ in the 6 to $<7$ h group, $201(9.9 \%)$ in the 7 to $<8 \mathrm{~h}$ group, and $59(11.2 \%)$ in the $\geq 8 \mathrm{~h}$ group.

Although the correlation was weak, the change of $\mathrm{Cr}$ was low and the change of eGFR was high in men with a shorter sleep duration $(r=0.0316$ and $p=0.006$ for change in $\mathrm{Cr}$ [Fig. 2] and $r=-0.0293$ and $p=0.01$ for change in eGFR [online suppl. Fig. S1; for all online suppl. material, see www.karger.com/doi/10.1159/000504545]).

Figure 3 shows the Kaplan-Meier curves for the proportion of participants without CKD progression according to sleep duration. A shorter sleep duration was associated with a significantly lower development of CKD in men ( $<6$ h group vs. 6 to $<7 \mathrm{~h}, 7$ to $<8 \mathrm{~h}$, and $\geq 8 \mathrm{~h}$ group: $p<0.0083 ; 6$ to $<7$ h group vs. 7 to $<8$ h group: $p<0.0083$ ]. There was no association between sleep duration and incident CKD in women $(p=0.894)$.

The results of multivariate analysis with the Cox proportional hazards model are shown in Table 2. In the men, compared to the 7 to $<8 \mathrm{~h}$ group, the HR of incident CKD were 0.54 (95\% CI $0.45-0.64, p<0.001)$ in the $<6$ h group, 0.73 (95\% CI 0.66-0.82, $p<0.001)$ in the 6 to $<7 \mathrm{~h}$ group, and 0.93 (95\% CI $0.78-1.11, p=0.433$ ) in the $\geq 8$ hroup after adjusting for potential covariates. There was no association between sleep duration and incident CKD in the women.

\section{Discussion}

The results of our analyses demonstrated that the HR of incident CKD were lowest in the men who reported sleeping $<6 \mathrm{~h}$. In line with our findings, the meta-analysis cited in the Introduction revealed that a short sleep duration tended to be associated with a low prevalence of 


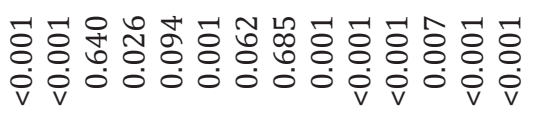

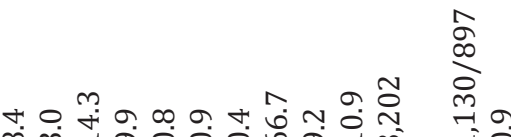

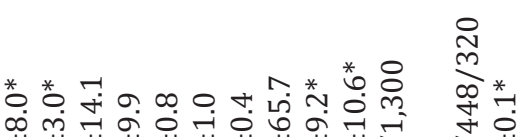

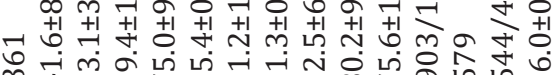
mi

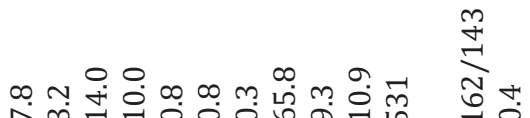

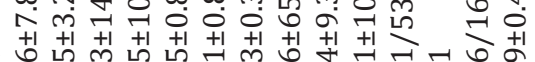

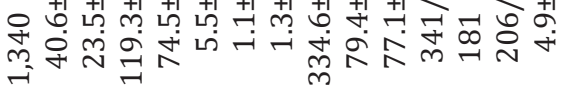

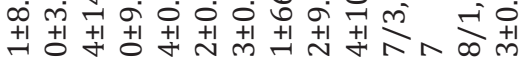

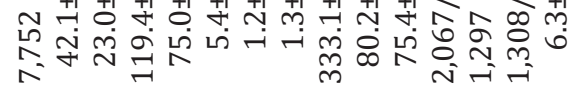

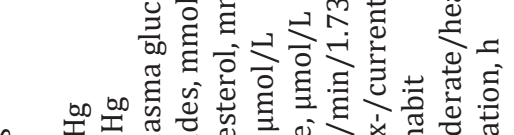

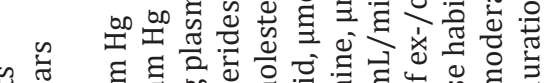

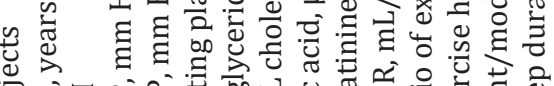

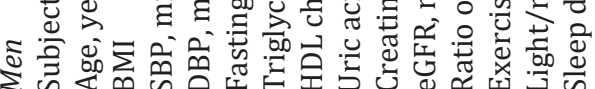

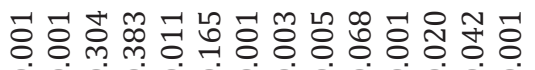

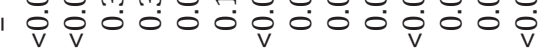

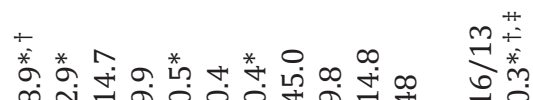

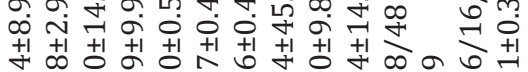

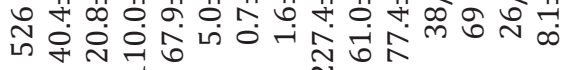

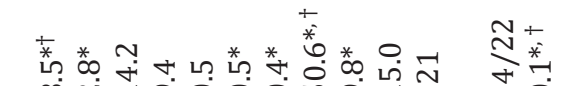

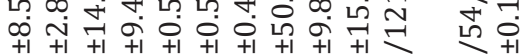

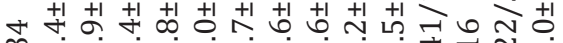

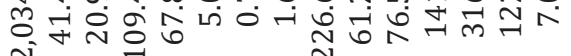

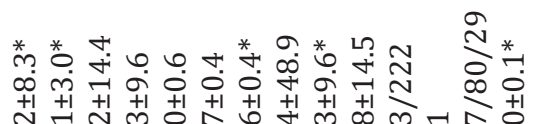
辛 ก

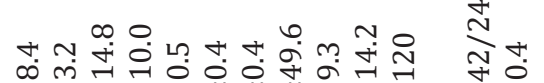

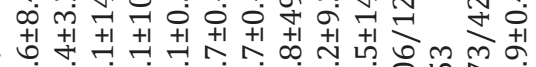

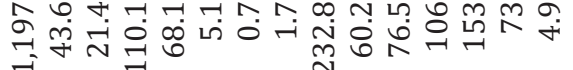

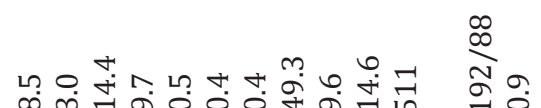

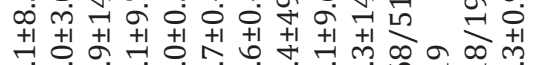
胥

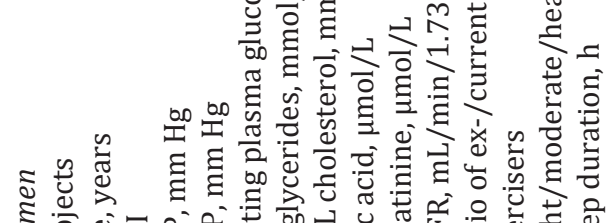

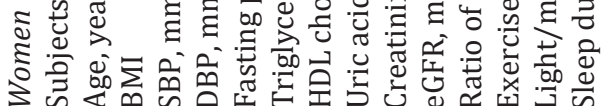

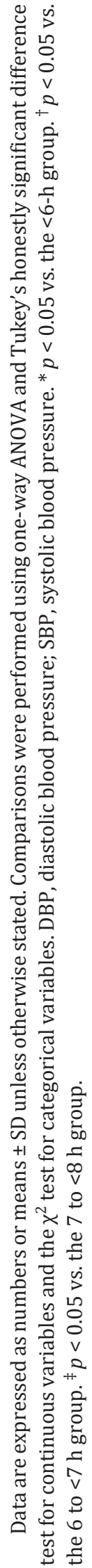




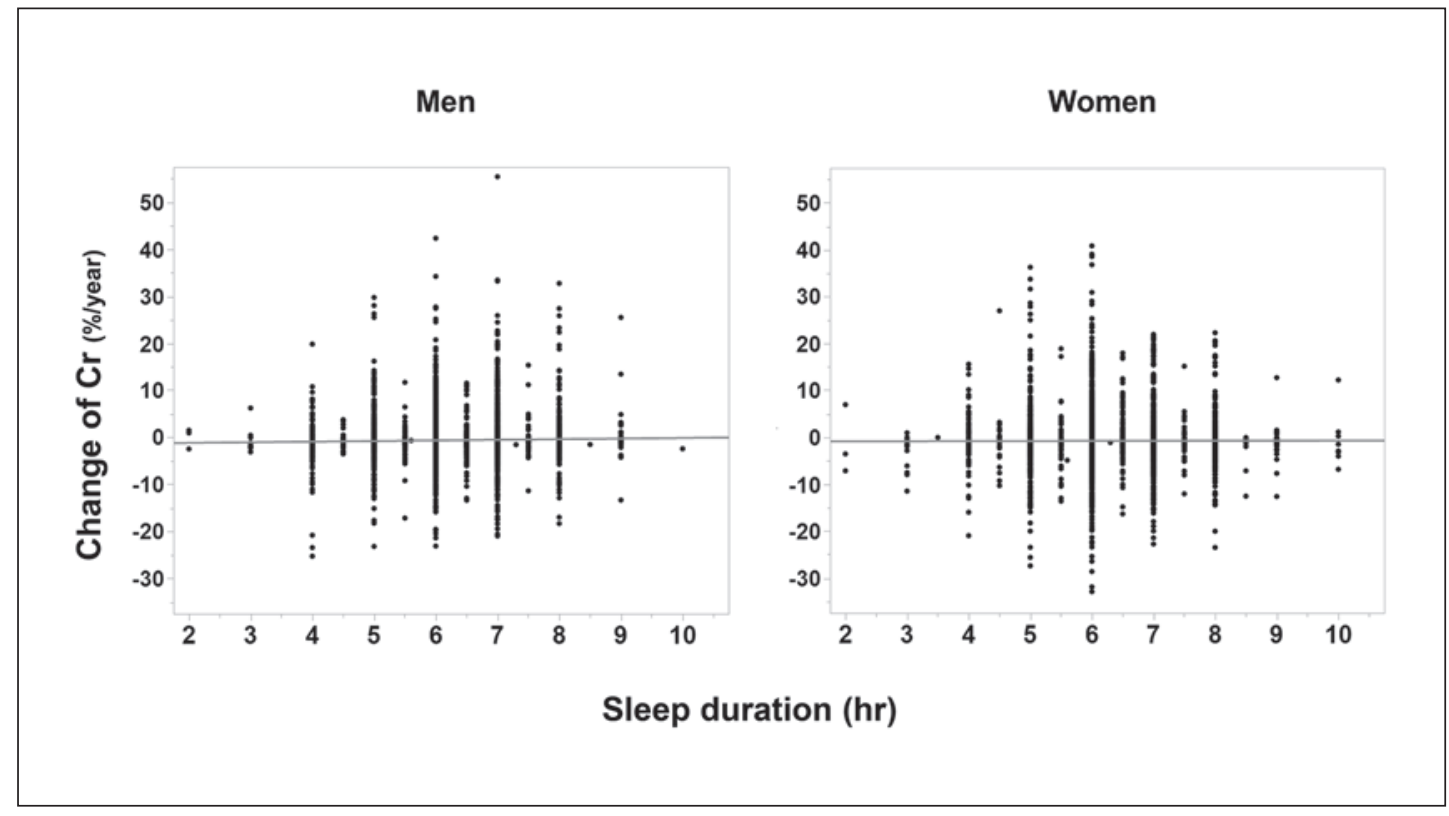

Fig. 2. Scatter plot and linear regression analysis of the correlation between sleep duration and change in $\mathrm{Cr}$. Change in $\mathrm{Cr}$ was defined as a percentage: ( $\mathrm{Cr}$ of the follow-up examination - $\mathrm{Cr}$ of the baseline examination)/ $\mathrm{Cr}$ of the baseline examination/follow-up duration (years). There was a correlation between change in $\mathrm{Cr}$ and sleep duration in men $(r=0.0316$ and $p=0.006)$. On the other hand, there was no correlation between change in $\mathrm{Cr}$ and sleep duration in women $(r=0.004, p=0.757)$.

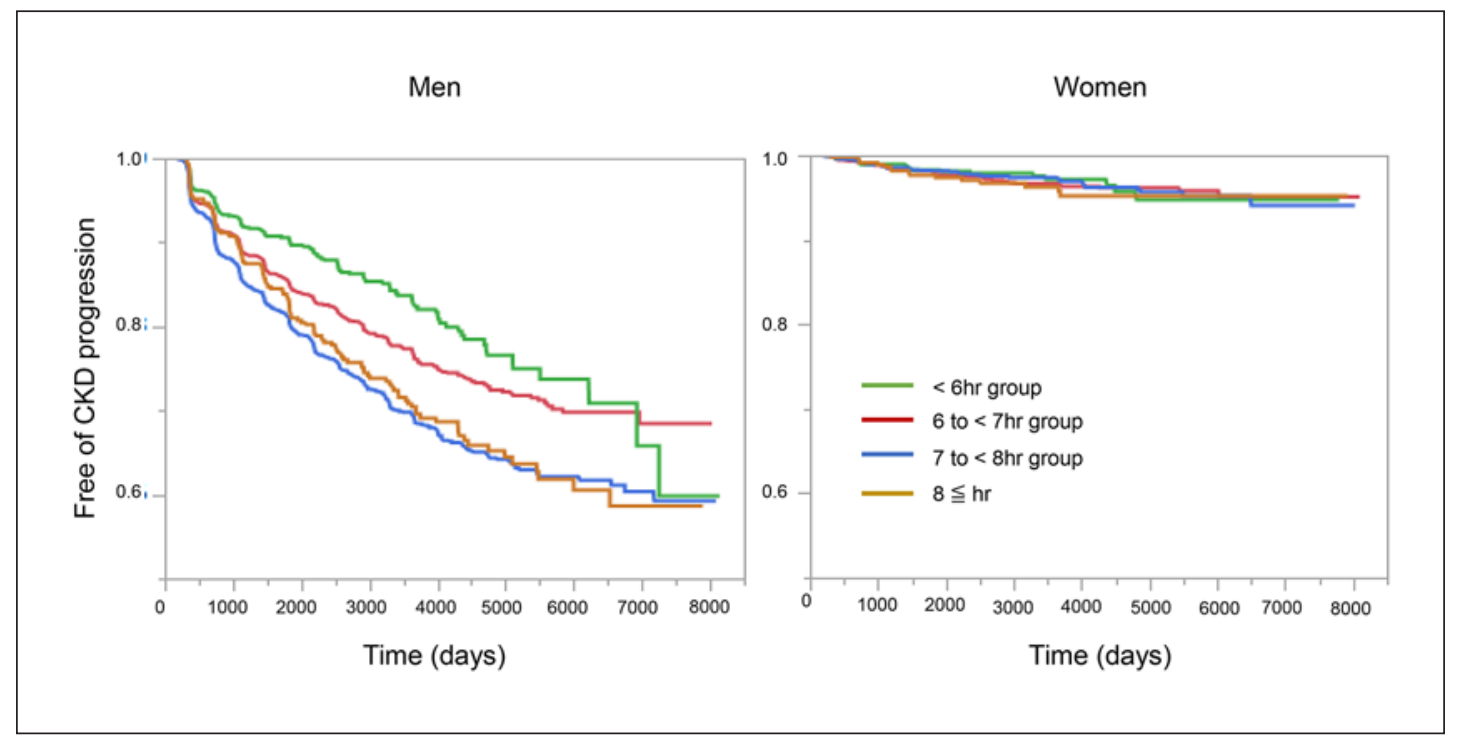

Fig. 3. Kaplan-Meier curves for freedom of CKD progression according to sleep duration. A log-rank test was used to assess differences among groups. To correct for family-wise error, we performed a Bonferroni correction and $p<0.0083$ was considered statistically significant in the log-rank test. A shorter sleep duration was associated with a significantly lower development of CKD in men ( $<6$ h group vs. $6-7 \mathrm{~h}, 7-8 \mathrm{~h}$, and $\geq 8 \mathrm{~h}$ groups: $p<0.0083$; 6-7 h group vs. $7-8$ h group: $p<0.0083$ ). There was no association between sleep duration and incident CKD in women $(p=0.894)$. 
Table 2. HR for incident CKD

\begin{tabular}{|c|c|c|}
\hline & HR $(95 \% \mathrm{CI})$ & $p$ \\
\hline \multicolumn{3}{|l|}{ Men } \\
\hline Age (years) & $1.06(1.05-1.06)$ & $<0.001$ \\
\hline BMI & $1.04(1.02-1.05)$ & $<0.001$ \\
\hline Uric acid $(10 \mu \mathrm{mol} / \mathrm{L})$ & $1.003(1.002-1.003)$ & $<0.001$ \\
\hline Creatinine $(\mu \mathrm{mol} / \mathrm{L})$ & $1.07(1.07-1.08)$ & $<0.001$ \\
\hline Triglycerides (mmol/L) & $1.14(1.10-1.17)$ & $<0.001$ \\
\hline HDL cholesterol (mmol/L) & $0.72(0.61-0.84)$ & $<0.001$ \\
\hline SBP (mm Hg) & $1.01(1.003-1.010)$ & 0.0001 \\
\hline Fasting plasma glucose (mmol/L) & $1.05(0.98-1.11)$ & 0.161 \\
\hline Exerciser & $1.22(1.07-1.38)$ & 0.004 \\
\hline Alcohol consumption & $1.04(1.02-1.07)$ & 0.0007 \\
\hline Ex-smoker & $1.24(1.10-1.42)$ & 0.0013 \\
\hline Current smoker & $1.02(0.90-1.15)$ & 0.807 \\
\hline \multicolumn{3}{|l|}{ Sleep duration } \\
\hline$<6 \mathrm{~h}$ group & $0.54(0.45-0.64)$ & $<0.001$ \\
\hline 6 to $<7$ h group & $0.73(0.66-0.82)$ & $<0.001$ \\
\hline 7 to $<8$ h group & 1.00 (reference) & - \\
\hline$\geq 8$ h group & $0.93(0.78-1.11)$ & 0.433 \\
\hline \multicolumn{3}{|l|}{ Women } \\
\hline Age (years) & $1.09(1.08-1.10)$ & $<0.001$ \\
\hline BMI & $1.08(1.05-1.10)$ & $<0.001$ \\
\hline Uric acid (10 $\mu \mathrm{mol} / \mathrm{L})$ & $1.007(1.006-1.009)$ & $<0.001$ \\
\hline Creatinine $(\mu \mathrm{mol} / \mathrm{L})$ & $1.07(1.06-1.08)$ & $<0.001$ \\
\hline Triglycerides (mmol/L) & $1.64(1.44-1.85)$ & $<0.001$ \\
\hline HDL cholesterol (mmol/L) & $0.94(0.76-1.16)$ & 0.550 \\
\hline SBP (mm Hg) & $1.02(1.015-1.025)$ & $<0.001$ \\
\hline Fasting plasma glucose $(\mathrm{mmol} / \mathrm{L})$ & $1.22(1.11-1.34)$ & $<0.001$ \\
\hline Exerciser & $1.55(1.30-1.86)$ & $<0.001$ \\
\hline Alcohol consumption & $0.96(0.92-1.00)$ & 0.044 \\
\hline Ex-smoker & $0.93(0.67-1.31)$ & 0.691 \\
\hline Current smoker & $1.17(0.89-1.55)$ & 0.245 \\
\hline \multicolumn{3}{|l|}{ Sleep duration } \\
\hline$<6 \mathrm{~h}$ group & $0.89(0.71-1.10)$ & 0.273 \\
\hline 6 to $<7$ h group & $1.16(0.97-1.38)$ & 0.103 \\
\hline 7 to $<8 \mathrm{~h}$ group & 1.00 (reference) & - \\
\hline$\geq 8$ h group & $1.08(0.81-1.45)$ & 0.584 \\
\hline
\end{tabular}

"No exercise habit" and "nonsmoker" were set as references for lifestyle factors.

CKD [13]. A strength of the present study is that we researched the longitudinal association between sleep duration and incident CKD in a large-scale cohort study of apparently healthy Japanese individuals. The reason why the result of this study is different from those of prior meta-analyses may stem from the characteristics of Japanese. The average sleep time of Japanese people is shorter than that of other ethnic groups [27], and this distinction can result in different study results.

Regarding with the association between sleep duration and mortality, it was reported that the mortality rate was lowest in individuals who regularly sleep $7 \mathrm{~h} \mathrm{[28].} \mathrm{The} \mathrm{authors} \mathrm{of}$ that study indicated a U-sharped curve between sleep length and subsequent mortality [28]. Later investigations showed that both short and long sleep durations were associated with mortality $[29,30]$.

Short sleep duration was also reported to be associated with the risk of hypertension [9], type 2 diabetes [10,11], obesity [12], and cardiovascular disease [15, 16], but another recent 


\section{Kidney \\ Blood Pressure \\ Research}

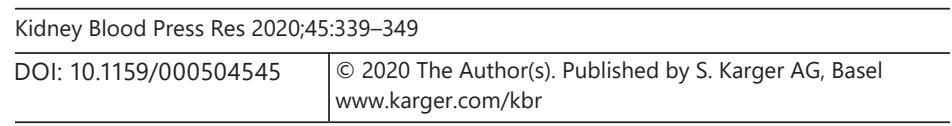

Nakajima et al.: CKD and Sleep Duration

meta-analysis including a meta-regression showed that a long sleep duration was associated with mortality, incident diabetes, cardiovascular disease, stroke, coronary heart disease, and obesity [31].

In CKD patients, neurological and cognitive impairments can be seen [32] and altered sleep habits are considered as one of the behavioral manifestations of brain changes in CKD. These have not been clarified, but in our present study, neurological changes may have had an influence on the sleep habit of the participants with incident CKD. In addition, sleep disturbances are associated with cognitive dysfunctions [33]. In fact, recent studies have revealed that even early CKD stages can be accompanied by cognitive dysfunctions [34], and thus sleep duration might be an early sign of CKD.

The precise mechanisms underlying how a short sleep duration affects incident CKD are not known, but some possibilities are as follows. A short sleep duration is associated with reduced leptin levels and elevated ghrelin levels [35]. Ghrelin, which has an anti-inflammatory effect [36], has a protective effect against renal fibrotic changes through the inhibition of angiotensin II-induced upregulation of transforming growth factor- $\beta$ and plasminogen activator inhibitor- 1 [37]. Moreover, leptin is associated with the progression of kidney diseases [38, 39]. Together these findings suggest that each sleep habit could affect incident CKD occurrence. Therefore, routine screening of renal function for patients with a sleep disturbance should be considered.

Some limitations of our study should be considered. First, the study population might have been comprised of mostly or only health-conscious individuals who undergo multiple health examinations, and this could have resulted in selection bias. Second, we defined proteinuria by dipstick testing, and thus the level of proteinuria was not quantified. We could not discuss urine occult blood, which could affect the amount of urine protein. However, the dipstick test is a useful tool, and it has been reported that most patients with a dipstick test result $\geq 1+$ have micro- or macroalbuminuria [24]. In addition, the presence of proteinuria shown by dipstick testing was reported to be a useful maker for future end-stage renal disease [40]. Third, our sleep duration data were based on a self-administered questionnaire, and the reliability of such self-reporting is a study limitation, although previous investigations of sleep duration have also been based on questionnaire responses [9-11,18]. We did not evaluate the quality of the subjects' sleep. Lastly, the generalizability of our research to non-Japanese populations is uncertain.

In conclusion, our analyses of 14,474 subjects showed that the risk of incident CKD is lowest for those who sleep $<6 \mathrm{~h}$ in apparently healthy men. That is why physicians should take note of altered sleep duration appropriately as an early sign of CKD, which would result in delaying the development of CKD.

\section{Acknowledgment}

We thank all of the staff members of the medical health checkup center at th eAsahi University Hospital.

\section{Statement of Ethics}

All of the procedures performed in studies involving human participants were in accordance with the ethical standards of the institutional and/or national research committee of the institute at which the studies were conducted and with the 1964 Helsinki Declaration and its later amendments or comparable ethical standards. Informed consent was obtained from all of the individual participants included in this study. This study was approved by the Medical Ethics Committee of the Asahi University Hospital. 


\section{Kidney \\ Blood Pressure \\ Research}

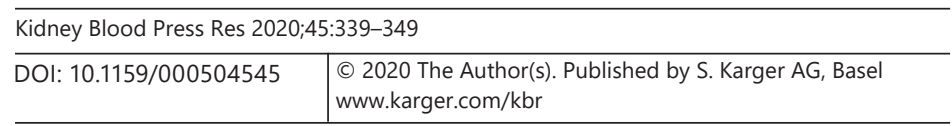

Nakajima et al.: CKD and Sleep Duration

\section{Disclosure Statement}

Y.H. has received grant support from Asahi Kasei Pharma and honoraria from Mitsubishi Tanabe Pharma Corporation and Novo Nordisk Pharma Ltd. M.H. has received grant support from Asahi Kasei Pharma, payment for development of educational presentations from MSD K.K., Mitsubishi Tanabe Pharma Corporation, Kowa Company Ltd., and Sumitomo Dainippon Pharma Co. Ltd., and royalties from US 10,238,714 B2. M.F. has received research support and payment for development of educational presentations from AstraZeneca plc., Astellas Pharma Inc., Nippon Boehringer Ingelheim Co., Ltd., Daiichi Sankyo Co., Ltd., Eli Lilly Japan K.K., Kyowa Hakko Kirin Company Ltd., Kissei Pharmaceutical Co., Ltd., MSD K.K., Sumitomo Dainippon Pharma Co. Ltd. Kowa Company Ltd., Mitsubishi Tanabe Pharma Corporation, Novo Nordisk Pharma Ltd., Sanwa Kagaku Kenkyusho Co. Ltd., Sanofi K.K., Ono Pharmaceutical Co. Ltd., Taisho Pharmaceutical Co. Ltd., Bayer Yakuhin Ltd., Mochida Pharmaceutical Co. Ltd., Johnson \& Johnson K.K. Medical Company, Nippon Chemiphar Co. Ltd., Terumo Corporation, Teijin Pharma Ltd., and Takeda Pharmaceutical Co. Ltd. These sponsors were not involved in the study design, the collection, analysis, and interpretation of data, the writing of this paper, or the decision to submit this article for publication. The other authors have nothing to disclose.

\section{Author Contributions}

H.N. contributed to the design of this work and analysis of the data and wrote this paper. Y.H. contributed to the conception and design of this work, analysis and interpretation of the data, and drafting of the Discussion. T.O. contributed to interpretation of the data and drafting of the Discussion. A.O. and T.K. contributed to the conception and design of this work, acquisition of data, and revision of the Discussion. M.H. contributed to the conception this work, acquisition and interpretation of data, and revision of the Discussion. M.F. contributed to the conception of this work, interpretation of data, and revision of the Discussion. M.H. is the guarantor of this work and, as such, had full access to all of the data in this study and takes responsibility for the integrity of the data and the accuracy of the data analysis. All of the authors gave final approval of the version to be published and agree to be accountable for all aspects of this work in ensuring that questions related to the accuracy or integrity of any part of this work are appropriately investigated and resolved.

\section{References}

1 Gansevoort RT, Correa-Rotter R, Hemmelgarn BR, Jafar TH, Heerspink HJ, Mann JF, et al. Chronic kidney disease and cardiovascular risk: epidemiology, mechanisms, and prevention. Lancet. 2013 Jul;382(9889): 339-52.

2 Weiner DE, Tighiouart H, Amin MG, Stark PC, MacLeod B, Griffith JL, et al. Chronic kidney disease as a risk factor for cardiovascular disease and all-cause mortality: a pooled analysis of community-based studies. J Am Soc Nephrol. 2004 May;15(5):1307-15.

3 Go AS, Chertow GM, Fan D, McCulloch CE, Hsu CY. Chronic kidney disease and the risks of death, cardiovascular events, and hospitalization. N Engl J Med. 2004 Sep;351(13):1296-305.

4 Iseki K. Chronic kidney disease in Japan. Intern Med. 2008;47(8):681-9.

5 McClellan WM, Flanders WD. Risk factors for progressive chronic kidney disease. J Am Soc Nephrol. 2003 Jul; 14(7 Suppl 2):S65-70.

6 Waxman A; World Health Assembly. WHO global strategy on diet, physical activity and health. Food Nutr Bull. 2004 Sep;25(3):292-302.

7 Hashimoto Y, Fukuda T, Oyabu C, Tanaka M, Asano M, Yamazaki M, et al. Impact of low-carbohydrate diet on body composition: meta-analysis of randomized controlled studies. Obes Rev. 2016 Jun;17(6):499-509. 
Nakajima et al.: CKD and Sleep Duration

8 Oyabu C, Hashimoto Y, Fukuda T, Tanaka M, Asano M, Yamazaki M, et al. Impact of low-carbohydrate diet on renal function: a meta-analysis of over 1000 individuals from nine randomised controlled trials. Br J Nutr. 2016 Aug;116(4):632-8.

9 Gangwisch JE, Heymsfield SB, Boden-Albala B, Buijs RM, Kreier F, Pickering TG, et al. Short sleep duration as a risk factor for hypertension: analyses of the first National Health and Nutrition Examination Survey. Hypertension. 2006 May;47(5):833-9.

10 Gottlieb DJ, Punjabi NM, Newman AB, Resnick HE, Redline S, Baldwin CM, et al. Association of sleep time with diabetes mellitus and impaired glucose tolerance. Arch Intern Med. 2005 Apr;165(8):863-7.

11 Cappuccio FP, D’Elia L, Strazzullo P, Miller MA. Quantity and quality of sleep and incidence of type 2 diabetes: a systematic review and meta-analysis. Diabetes Care. 2010 Feb;33(2):414-20.

12 Cappuccio FP, Taggart FM, Kandala NB, Currie A, Peile E, Stranges S, et al. Meta-analysis of short sleep duration and obesity in children and adults. Sleep. 2008 May;31(5):619-26.

13 Okamura T, Hashimoto Y, Hamaguchi M, Obora A, Kojima T, Fukui M. Short sleep duration is a risk of incident nonalcoholic fatty liver disease: a population-based longitudinal study. J Gastrointestin Liver Dis. 2019 Mar;28(1):73-81.

14 Miyake T, Kumagi T, Furukawa S, Hirooka M, Kawasaki K, Koizumi M, et al. Short sleep duration reduces the risk of nonalcoholic fatty liver disease onset in men: a community-based longitudinal cohort study. J Gastroenterol. 2015 May;50(5):583-9.

15 Sabanayagam C, Shankar A. Sleep duration and cardiovascular disease: results from the National Health Interview Survey. Sleep. 2010 Aug;33(8):1037-42.

16 Cappuccio FP, Cooper D, D’Elia L, Strazzullo P, Miller MA. Sleep duration predicts cardiovascular outcomes: a systematic review and meta-analysis of prospective studies. Eur Heart J. 2011 Jun;32(12):1484-92.

17 Cheungpasitporn W, Thongprayoon C, Gonzalez-Suarez ML, Srivali N, Ungprasert P, Kittanamongkolchai W, et al. The effects of short sleep duration on proteinuria and chronic kidney disease: a systematic review and meta-analysis. Nephrol Dial Transplant. 2017 Jun;32(6):991-6.

18 Sasaki S, Yoshioka E, Saijo Y, Kita T, Tamakoshi A, Kishi R. Short sleep duration increases the risk of chronic kidney disease in shift workers. J Occup Environ Med. 2014 Dec;56(12):1243-8.

19 Hamaguchi M, Kojima T, Takeda N, Nakagawa T, Taniguchi H, Fujii K, et al. The metabolic syndrome as a predictor of nonalcoholic fatty liver disease. Ann Intern Med. 2005 Nov;143(10):722-8.

20 Hashimoto Y, Hamaguchi M, Tanaka M, Obora A, Kojima T, Fukui M. Metabolically healthy obesity without fatty liver and risk of incident type 2 diabetes: A meta-analysis of prospective cohort studies. Obes Res Clin Pract. 2018 Jan - Feb;12(1):4-15.

21 Okamura T, Hashimoto Y, Hamaguchi M, Ohbora A, Kojima T, Fukui M. Metabolically healthy obesity and risk of leukoaraiosis; a population based cross-sectional study. Endocr J. 2018 Jun;65(6):669-75.

22 Ryu S, Chang Y, Kim DI, Kim WS, Suh BS. gamma-Glutamyltransferase as a predictor of chronic kidney disease in nonhypertensive and nondiabetic Korean men. Clin Chem. 2007 Jan;53(1):71-7.

23 Matsuo S, Imai E, Horio M, Yasuda Y, Tomita K, Nitta K, et al.; Collaborators developing the Japanese equation for estimated GFR. Revised equations for estimated GFR from serum creatinine in Japan. Am J Kidney Dis. 2009 Jun;53(6):982-92.

24 Konta T, Hao Z, Takasaki S, Abiko H, Ishikawa M, Takahashi T, et al. Clinical utility of trace proteinuria for microalbuminuria screening in the general population. Clin Exp Nephrol. 2007 Mar;11(1):51-5.

25 Hashimoto Y, Tanaka M, Okada H, Senmaru T, Hamaguchi M, Asano M, et al. Metabolically healthy obesity and risk of incident CKD. Clin J Am Soc Nephrol. 2015 Apr;10(4):578-83.

26 Satoh H, Nishihira J, Wada T, Fujii S, Tsutui H. The relation between habitual sleep duration and blood pressure values in Japanese male subjects. Environ Health Prev Med. 2013 May;18(3):215-20.

27 OECD. OECD Gender Data Portal [Internet]. 2019. Available from: https://www.oecd.org/gender/data/ OECD_1564_TUSupdatePortal.xlsx.

28 Hammond EC. Some preliminary findings on physical complaints from a prospective study of 1,064,004 men and women. Am J Public Health Nations Health. 1964 Jan;54(1):11-23.

29 Hublin C, Partinen M, Koskenvuo M, Kaprio J. Sleep and mortality: a population-based 22-year follow-up study. Sleep. 2007 Oct; 30(10):1245-53.

30 Yu JH, Han K, Kim NH, Yoo HJ, Seo JA, Kim SG, et al. U-shaped association between sleep duration and urinary albumin excretion in Korean adults: 2011-2014 Korea National Health and Nutrition Examination Survey. PLoS One. 2018 Feb;13(2):e0192980.

31 Jike M, Itani O, Watanabe N, Buysse DJ, Kaneita Y. Long sleep duration and health outcomes: a systematic review, meta-analysis and meta-regression. Sleep Med Rev. 2018 Jun;39:25-36.

32 Viggiano D, Wagner CA, Blankestijn PJ, Bruchfeld A, Fliser D, Fouque D, et al. Mild cognitive impairment and kidney disease: clinical aspects. Nephrol Dial Transplant. 2019 Apr;9:1-8.

33 Shi L, Chen SJ, Ma MY, Bao YP, Han Y, Wang YM, et al. Sleep disturbances increase the risk of dementia: a systematic review and meta-analysis. Sleep Med Rev. 2018 Aug;40:4-16.

34 Mujais SK, Story K, Brouillette J, Takano T, Soroka S, Franek C, et al. Health-related quality of life in CKD Patients: correlates and evolution over time. Clin J Am Soc Nephrol. 2009 Aug;4(8):1293-301.

35 Taheri S, Lin L, Austin D, Young T, Mignot E. Short sleep duration is associated with reduced leptin, elevated ghrelin, and increased body mass index. PLoS Med. 2004 Dec;1(3):e62.

36 Baatar D, Patel K, Taub DD. The effects of ghrelin on inflammation and the immune system. Mol Cell Endocrinol. 2011 Jun;340(1):44-58. 
37 Fujimura K, Wakino S, Minakuchi H, Hasegawa K, Hosoya K, Komatsu M, et al. Ghrelin protects against renal damages induced by angiotensin-II via an antioxidative stress mechanism in mice. PLoS One. 2014 Apr; 9(4):e94373.

38 D’Elia L, Manfredi M, Perna L, Iacone R, Russo O, Strazzullo P, et al. Circulating leptin levels predict the decline in renal function with age in a sample of adult men (The Olivetti Heart Study). Intern Emerg Med. 2019 Jun; 14(4):507-13.

39 Gunta SS, Mak RH. Ghrelin and leptin pathophysiology in chronic kidney disease. Pediatr Nephrol. 2013 Apr; 28(4):611-6.

40 Ishani A, Grandits GA, Grimm RH, Svendsen KH, Collins AJ, Prineas RJ, et al. Association of single measurements of dipstick proteinuria, estimated glomerular filtration rate, and hematocrit with 25-year incidence of endstage renal disease in the multiple risk factor intervention trial. J Am Soc Nephrol. 2006 May;17(5):1444-52. 